\title{
On the role of hippocampal protein synthesis in the consolidation and reconsolidation of object recognition memory
}

\author{
Janine I. Rossato, Lia R.M. Bevilaqua, Jociane C. Myskiw, Jorge H. Medina, \\ Iván Izquierdo, and Martín Cammarota ${ }^{1}$ \\ Centro de Memória, Instituto de Pesquisas Biomédicas, Pontifícia Universidade Católica do Rio Grande do Sul, Porto Alegre, \\ RS 90610-000, Brasil and Laboratorio de Neuroreceptores, Instituto de Biología Celular y Neurociencias "Prof. Dr. Eduardo \\ de Robertis," Facultad de Medicina, Universidad de Buenos Aires, Paraguay $21553^{\circ}$ Piso, Ciudad Autónoma de Buenos Aires, \\ CP 1121, Argentina
}

\begin{abstract}
Upon retrieval, consolidated memories are again rendered vulnerable to the action of metabolic blockers, notably protein synthesis inhibitors. This has led to the hypothesis that memories are reconsolidated at the time of retrieval, and that this depends on protein synthesis. Ample evidence indicates that the hippocampus plays a key role both in the consolidation and reconsolidation of different memories. Despite this fact, at present there are no studies about the consequences of hippocampal protein synthesis inhibition in the storage and post-retrieval persistence of object recognition memory. Here we report that infusion of the protein synthesis inhibitor anisomycin in the dorsal CAl region immediately or 180 min but not 360 min after training impairs consolidation of long-term object recognition memory without affecting short-term memory, exploratory behavior, anxiety state, or hippocampal functionality. When given into CAl after memory reactivation in the presence of familiar objects, ANI did not affect further retention. However, when administered into CAl immediately after exposing animals to a novel and a familiar object, ANI impaired memory of both of them. The amnesic effect of ANI was long-lasting, did not happen after exposure to two novel objects, following exploration of the context alone, or in the absence of specific stimuli, suggesting that it was not reversible but was contingent on the reactivation of the consolidated trace in the presence of a salient, behaviorally relevant novel cue. Our results indicate that hippocampal protein synthesis is required during a limited post-training time window for consolidation of object recognition memory and show that the hippocampus is engaged during reconsolidation of this type of memory, maybe accruing new information into the original trace.
\end{abstract}

Memories are not established in their definitive form right after acquisition. Instead, they undergo a protracted protein synthesisdependent consolidation process during which the originally fragile and vulnerable trace is progressively stabilized into a lasting and disruption-resistant long-term memory (LTM; McGaugh 1966). Although in its original formulation the consolidation hypothesis stated that consolidation occurs only once for each memory item and so once the mnemonic trace had been consolidated it became immune to subsequent disruption (McGaugh 1966; Squire and Alvarez 1995), this assumption was challenged early on (Misanin et al. 1968; Mactutus et al. 1979; but see Dawson and McGaugh 1969). Since then, it has been repeatedly proposed that upon non-reinforced reactivation, LTM can be rendered again vulnerable to pharmacological disruption (Judge and Quartermain 1982; Przybyslawski and Sara 1997; Nader et al. 2000a; Milekic and Alberini 2002), and that in order to persist, it must undergo a new protein synthesis-dependent stabilization phase referred to as reconsolidation (Sara 2000; Nader 2003; Eisenberg and Dudai 2004; Lee et al. 2004). Initially restricted to a particular form of fear-motivated task in the rat, reconsolidation has now been described using other learning paradigms and different animal models (Debiec et al. 2002; Kida et al. 2002; Eisenberg et al. 2003; Sangha et al. 2003; Gainutdinova et al.

${ }^{1}$ Corresponding author.

E-mail mcammaro@terra.com.br; fax 55-51-33203312.

Article is online at http://www.learnmem.org/cgi/doi/10.1101//m.422607.
2005; Inda et al. 2005; Merlo et al. 2005; Stollhoff et al. 2005; Rossato et al. 2006). Despite this evidence, the existence of memory reconsolidation is not unanimously accepted, and several laboratories have failed to detect it in well-known learning paradigms (Squire et al. 1976; Biedenkapp and Rudy 2004; Cammarota et al. 2004; Hernandez and Kelley 2004; Lattal and Abel 2004; Power et al. 2006).

Recognition memory confers the ability to discriminate between novel and familiar entities. Neuropsychological analysis of amnesic patients as well as lesion experiments with non-human primates and rodents indicate that the functional integrity of the temporal lobe is essential for encoding, storage, and expression of this type of memory (Logothetis and Sheinberg 1996; Riesenhuber and Poggio 2002). However, it is still not clear which temporal lobe structures are directly involved in the consolidation and retrieval of object recognition memory. In particular, the role played by the hippocampus in these processes remains controversial. It has been reported that hippocampal lesions affect neither object recognition (Winters et al. 2004) nor object recognition memory in a delayed nonmatching-to-sample task in rats (Mumby 2001), although studies using longer retention delays (Clark et al. 2000) or behavioral paradigms relying on novelty preference (Ennaceur and Delacour 1988) indicate that damage to the hippocampal formation does indeed impair this type of memory. The cause for these discrepancies is not clear, but it must be taken into account that a major drawback of the abovementioned studies was that, as a result of using irreversible le- 

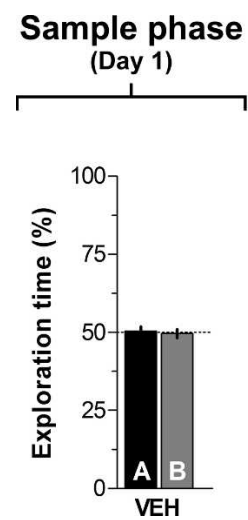

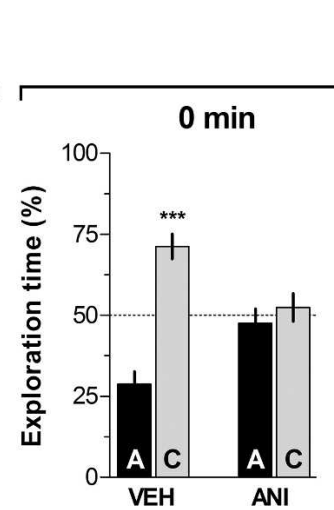

\section{Test phase (Day 2)}

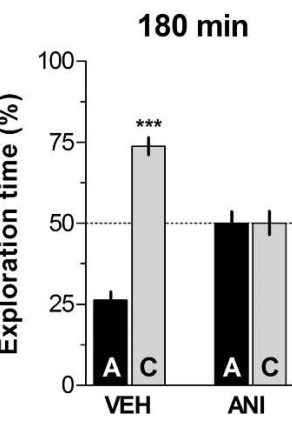

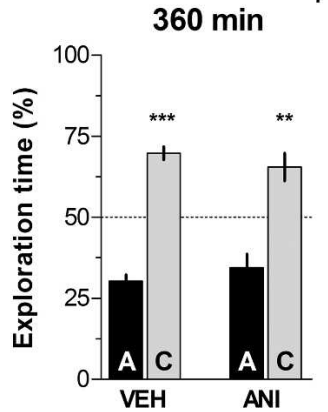

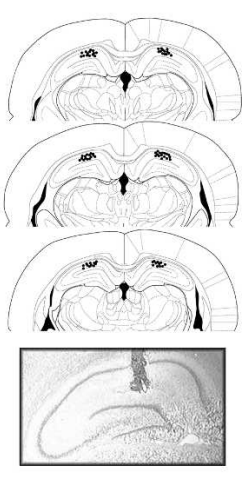

Figure 1. Hippocampal protein synthesis is required during a restricted post-training time window for consolidation of object recognition memory. On day 1 (sample phase) rats $(n=74)$ were exposed to two different objects (A and B) for 5 min and at different times after that $(0,180$, or 360 min) received bilateral infusions $(0.8 \mu \mathrm{L} /$ side) of vehicle ( $\mathrm{VEH}$; saline) or anisomycin ( $\mathrm{ANI} ; 160 \mu \mathrm{g} /$ side) in the $\mathrm{CA} 1$ region of the dorsal hippocampus. On day 2 (Test phase) animals were exposed to a familiar $(A)$ and a novel object (C) for an additional 5 min. Data are presented as mean ( \pm SEM) of the percentage of time exploring a particular object over the total time of object exploration. ${ }^{* * *} P<0.0005,{ }^{* *} P<0.005$ in Student's $t$-test; $n=10-15$ per group. Note that animals that received ANI immediately or $180 \mathrm{~min}$ after training spent the same amount of time exploring objects $\mathrm{A}$ and $\mathrm{C}$ during the test phase (Day 2; 0 min-ANI and 180 min-ANI) indicating that recognition memory was impaired. (Right) Schematic drawings taken from the atlas of Paxinos and Watson (1986) and representative photomicrograph showing the location of the infusion cannulae tips in dorsal CA1 for the animals that received post-training ANI.

sions inflicted either before or after training, they could not discriminate among the different phases of memory processing or easily exclude non-specific behavioral and physiological effects.

The aim of the present study was to evaluate the requirement of hippocampal protein synthesis for the normal consolidation of object recognition memory and to investigate whether retrieval of this type of memory initiates in the hippocampus a protein synthesis-dependent process that affects subsequent retention of the mnemonic trace. To do that we used a noveltypreference paradigm based on the rats' natural preference to explore novel objects (Ennaceur and Delacour 1988; Ennaceur and Aggleton 1994; Ennaceur et al. 1996, 1997; Mumby et al. 2002a,b; Gaskin et al. 2003) and analyzed whether the intrahippocampal infusion of the protein synthesis inhibitor anisomycin (ANI) at different times after training or retrieval affects memory retention.

\section{Results}

To analyze whether hippocampal protein synthesis is necessary for recognition memory consolidation, rats were trained in an object recognition task and, at different times after the sample phase on day 1, received bilateral intra-CA1 infusions of ANI (160 $\mu \mathrm{g} /$ side) or vehicle. Memory retention was tested $24 \mathrm{~h}$ posttraining. During this test phase, animals were exposed for $5 \mathrm{~min}$ to one of the familiar objects that had been presented during the sample phase, plus a novel object. The rats that had received intra-CA1 vehicle after the sample phase showed significantly longer exploration of the novel object than of the familiar one $\left(P<0.0005\right.$ in Student's $t$-test; $t_{[13]}=5.54 ; t_{[9]}=8.97$ and $t_{[9]}=9.77$ for animals infused at 0,180 , and 360 min posttraining, respectively). However, animals that received intra-CA1 ANI immediately (0 min) or $180 \mathrm{~min}$ but not $360 \mathrm{~min}$ after training spent the same amount of time exploring the novel and the familiar objects in the test phase (Fig. 1; Test phase-Day 2). So, inhibition of hippocampal protein synthesis early after training blocked consolidation of long-term recognition memory.

In another set of experiments, rats were trained as indicated above and received intra-CA1 ANI (160 $\mu \mathrm{g} /$ side) or vehicle right after training, but were tested $3 \mathrm{~h}$ post-training to evaluate shortterm memory (STM) retention. As can be seen in Figure 2, both control and ANI-treated animals showed preference for the novel object during the test phase $(P<0.0005$ in Student's $t$-test; $t_{[7]}=11.30$ and $t_{[7]}=8.62$, respectively). Thus, inhibition of hippocampal protein synthesis right after training had no effect on object recognition STM.

In order to evaluate whether intra-CA1 ANI had any protracted action on anxiety state or in exploratory activity that could mask retrieval of long-term memory, rats were given intraCA1 vehicle or ANI and submitted to a plus maze or an open field session $24 \mathrm{~h}$ afterward. When infused into dorsal CA1 $24 \mathrm{~h}$ before a 5 -min plus-maze session, ANI $(160 \mu \mathrm{g} /$ side $)$ had no effect on the total number of entries, on the number of entries into the open arms, or on the percentage of time spent in the open arms. Similarly, intra-CA1 ANI did not affect the number of crossings and rearings when given into CA1 $24 \mathrm{~h}$ before a 5-min freeexploration open field session (Table 1). Rats that received intraCA1 ANI did not show any lingering perceptual impairment $24 \mathrm{~h}$ after the injection. In fact, when trained in the spatial version of
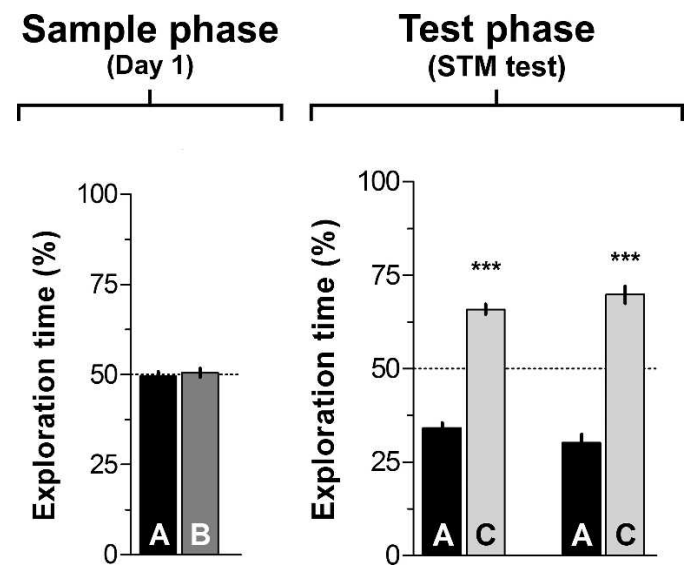

Figure 2. Post-training inhibition of hippocampal protein synthesis does not affect short-term object recognition memory. Rats $(n=16)$ were exposed to two different objects (A and B) for 5 min and immediately after that received bilateral infusions $(0.8 \mu \mathrm{L} /$ side $)$ of vehicle $(\mathrm{VEH}$; saline) or anisomycin (ANI; $160 \mu \mathrm{g} / \mathrm{side}$ ) in the CA1 region of the dorsal hippocampus. Three hours later (Test phase/STM test) animals were exposed to a familiar object (A) and a novel object (C) for an additional 5 min. Data are presented as mean $( \pm S E M)$ of the percentage of time exploring a particular object over the total time of object exploration. ${ }^{* * *} P<0.0005$ in Student's $t$-test; $n=8$ per group. 
Table 1. Infusion of anisomycin into the CA1 region of the dorsal hippocampus has no effect on locomotor and exploratory activities or anxiety state

\begin{tabular}{lrr}
\hline & \multicolumn{1}{c}{ VEH } & \multicolumn{1}{c}{ ANI } \\
\hline Total entries & $20.3 \pm 1.9$ & $18.2 \pm 1.5$ \\
Entries in open arms & $8.2 \pm 0.9$ & $9.0 \pm 0.7$ \\
$\%$ time in open arms & $25.6 \pm 4.1$ & $28.5 \pm 4.8$ \\
Crossings & $77.3 \pm 6.8$ & $74.6 \pm 8.1$ \\
Rearings & $18.8 \pm 2.0$ & $23.6 \pm 3.9$ \\
\hline
\end{tabular}

ANI $(160 \mu \mathrm{g} /$ side) was bilaterally infused $(0.8 \mu \mathrm{L} /$ side) into the CA1 region of the dorsal hippocampus $24 \mathrm{~h}$ before an open field or a plus maze session. Data are expressed as mean ( \pm SEM) of the total number of entries, the number of entries into the open arms, and the percentage of time spent in the open arms (plus maze; $n=10$ per group) and of the number of crossings and rearings (open field; $n=10$ per group). A different set of animals was utilized for each behavioral test.

(VEH) vehicle; (ANI) anisomycin.

the Morris Water Maze, they acquired (Fig. 3A) and retained (Fig. 3B) a spatial preference as quickly and unfailingly as control animals did. Similarly, when trained in a one-trial stepdown avoidance learning task, rats that had received intra-CA1 ANI $24 \mathrm{~h}$ before normally learned the aversive conditioned response (Fig. 3C).

As mentioned, many studies indicate that after retrieval consolidated memories become vulnerable again, and in order to persist must go through a protein synthesis-dependent process named reconsolidation (Nader et al. 2000b; Eisenberg and Dudai 2004). Some reports also suggest that reconsolidation may require similar molecular mechanisms and engage the same brain regions as consolidation (Przybyslawski and Sara 1997; Przybyslawski et al. 1999; Sara 2000; Kida et al. 2002; Pedreira et al. 2002; Bozon et al. 2003). Therefore, to test whether inhibition of hippocampal protein synthesis after retrieval of recognition
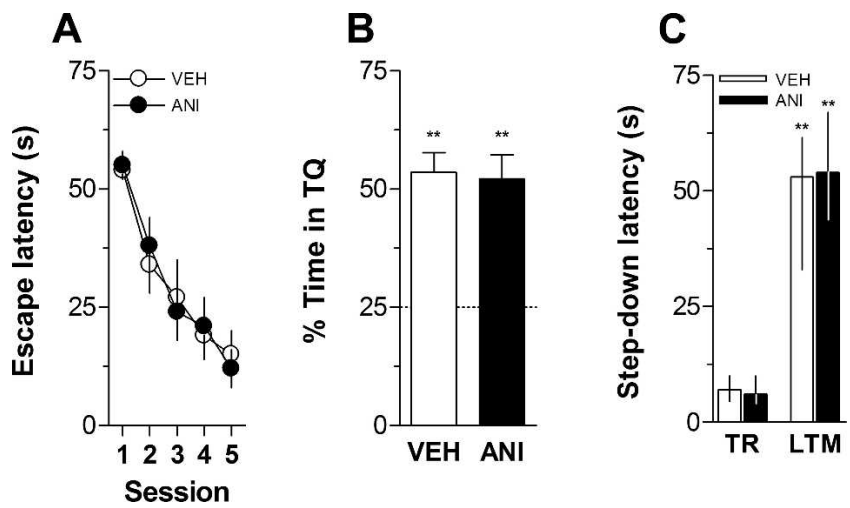

Figure 3. Inhibition of hippocampal protein synthesis $24 \mathrm{~h}$ before training does not affect acquisition or retention of hippocampaldependent memories. (A) Mean escape latency during the $5 \mathrm{~d}$ of acquisition of spatial learning for rats $(n=16)$ given anisomycin $(160 \mu \mathrm{g} / \mathrm{side}$; $\mathrm{ANI}$; black circles) or vehicle (VEH; white circles) in the CA1 region of the dorsal hippocampus $24 \mathrm{~h}$ before the first training session. Data are presented in blocks of eight trials as mean \pm SEM. (B) Percentage of time spent in the target quadrant (TQ) during a $60-\mathrm{sec}$ probe test carried out $24 \mathrm{~h}$ after the fifth training day for the rats shown in $A$. Data are presented as mean \pm SEM. ${ }^{* *} P<0.005$ in one-sample Student's $t$-test (reference value $=25 \%)(C)$ Rats with infusion cannulae implanted in the CA1 region of the dorsal hippocampus $(n=18)$ received intra-CA1 infusions of anisomycin $(160 \mu \mathrm{g} / \mathrm{side}$; $\mathrm{ANI})$ or vehicle (VEH) and $24 \mathrm{~h}$ afterward were trained in a one-trial, step-down inhibitory avoidance task. Data are presented as median \pm interquartile range of step-down latency in the training session (TR) and during a long-term memory (LTM) retention test session performed $24 \mathrm{~h}$ post-training. ${ }^{* *} P<0.005$ vs. the respective TR value in a Mann-Whitney U-test. memory disrupts the stability of the reactivated trace, we exposed rats to two different objects on day 1 (sample phase). On day 2 (reactivation phase), rats were reexposed to the same two objects for $5 \mathrm{~min}$ in order to reactivate the recognition memory trace, and, immediately after that, they received bilateral infusions of ANI $(160 \mu \mathrm{g} /$ side) or vehicle in dorsal CA1. If hippocampal protein synthesis was necessary for reconsolidation of recognition memory, then it would be expected that, when challenged with a familiar and a novel object $1 \mathrm{~d}$ after reactivation, animals that had received ANI at the end of the reactivation phase should not show preference for any object and equally explore both of them. However, as can be seen in Figure $4 \mathrm{~A}$, when confronted with a familiar and a novel object on day 3 (Fig. 4A; Test phase, 0 min), both vehicle- and ANI-treated animals showed preferential exploration of the novel object $(P<0.0005$ in Student's $t$-test; $t_{[9]}=7.90$ and $t_{[12]}=6.18$, respectively), indicating that memory of the familiar object had not been disrupted by inhibition of hippocampal protein synthesis. A complete lack of effect on memory persistence was also obtained when ANI was given into dorsal CA1 at either $180\left(P<0.0005 ; t_{[9]}=7.14\right.$ and $t_{[9]}=12.55$ for VEH- and ANI-infused animals) or 360 min after reactivation $\left(P<0.0005 ; t_{[9]}=5.26\right.$ and $t_{[9]}=7.98$ for VEH- and ANI-infused animals) (Fig. 4A; Test phase, $180 \mathrm{~min}$ and $360 \mathrm{~min}$ ).

It has been suggested that the post-retrieval effect of some amnesic agents depends on both the duration of the reactivation session and the age of the mnemonic trace. Therefore, in order to analyze whether a shorter reactivation session was able to initiate reconsolidation of recognition memory, rats were trained as indicated above and $24 \mathrm{~h}$ later were submitted to a 2-min-long reactivation session. Right after that session, animals received bilateral intra-CA1 infusions of vehicle or ANI (160 $\mu \mathrm{g} / \mathrm{side})$, and retention was evaluated $24 \mathrm{~h}$ later. Vehicle- $\left(P<0.05 ; t_{[9]}=3.12\right)$ and ANI-treated animals $\left(P<0.005 ; t_{[9]}=5.23\right)$ spent more time exploring the novel than the familiar object (Fig. 4B; Test phase). This suggests that the length of the reactivation session has no influence on the lack of effect of the post-retrieval intra-CA1 infusion of ANI on memory persistence.

To investigate whether the occurrence of reconsolidation was dependent on the age of the recognition memory trace, rats trained in the object recognition task were submitted to a reactivation session $5 \mathrm{~d}$ post-training. Immediately after that, they received vehicle or ANI (160 $\mu \mathrm{g} / \mathrm{side})$ in the CA1 region, and memory retention was measured $24 \mathrm{~h}$ post-reactivation. As can be seen in Figure 4C, the age of the memory had no effect on the lack of action of ANI on retention $\left(P<0.0005, t_{[10]}=7.99\right.$ and $P<0.005, t_{[10]}=3.28$ for vehicle- and ANI-treated animals, respectively).

The disrupting effect of protein synthesis inhibition on the persistence of reactivated memories has been observed mostly after non-reinforced retrieval, but not when the reactivation session was either a pure retrieval session (i.e., a session in which memory is expressed but the possibility of extinction is neutrally prevented; Cammarota et al. 2004) or a reactivation session in the presence of exactly the same retrieval cues and stimuli as during the training session (i.e., a second training session; Cammarota et al. 2003; Eisenberg and Dudai 2004; Gainutdinova et al. 2005). Note that this last example perfectly applies to the design of the experiments presented in Figure 4.

Inhibition of protein synthesis after memory reactivation has also been shown to impair further retention when the reinforcer, even if present during reactivation, does not match exactly the expectations derived from original learning (Rossato et al. 2006). This observation suggests that reconsolidation would act not only to save the trace from destabilization induced by non-reinforced retrieval but, importantly, would also help to incorporate new information into already consolidated memories 


\section{A}
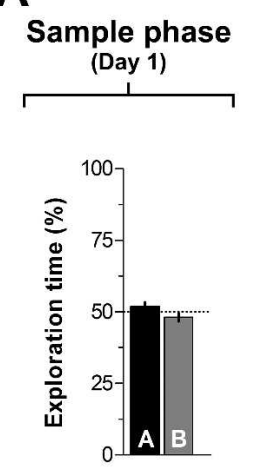
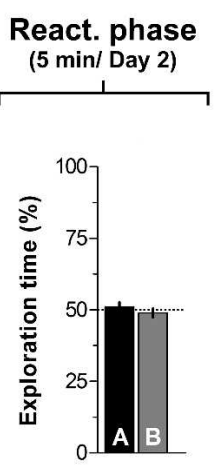

Test phase

(Day 3)

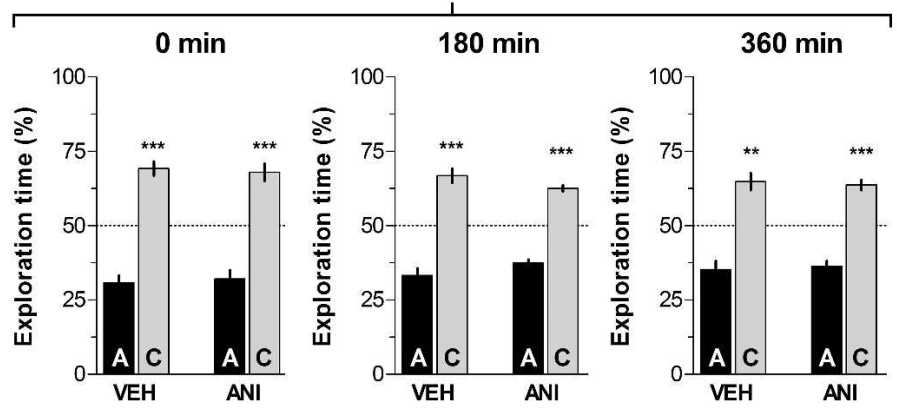

B

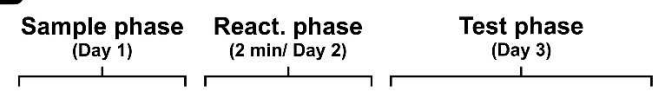

C
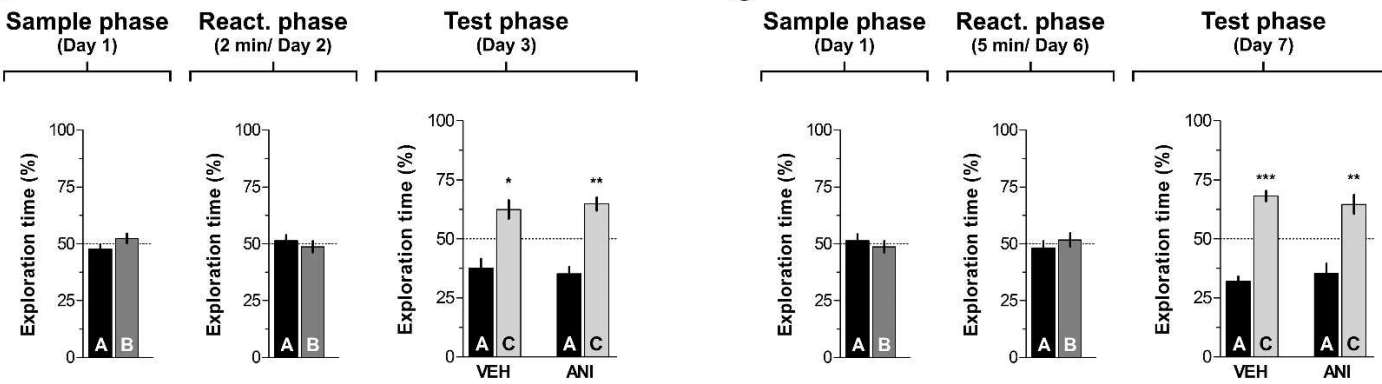

Figure 4. Inhibition of hippocampal protein synthesis after a reactivation session involving exposition to familiar objects does not affect further retention of recognition memory. $(A)$ Rats with infusion cannulae implanted in the CA1 region of the dorsal hippocampus $(n=64)$ were exposed to two objects (A and B) for 5 min (Sample phase, Day 1). Twenty-four hours later the animals were re-exposed for an additional 5 min to the same two objects to reactivate the memory trace (Reactivation phase, Day 2$)$, and at different times after that (0, 180 , or 360 min) received bilateral intra-CA1 infusions of anisomycin $(160 \mu \mathrm{g} /$ side; ANI) or vehicle (VEH). Retention was assessed $24 \mathrm{~h}$ later by exposing animals to the familiar object A plus a novel object $C$ (Test phase, Day 3). Note that regardless of the treatment and the moment of infusion, animals spent more time exploring the novel than the familiar object, indicating that memory had been preserved. ${ }^{* *} P<0.0005,{ }^{* *} P<0.005$ in Student's $t$-test; $n=10-13$ per group. (B) Animals $(n=20)$ were treated as in $A$ except that the reactivation session was just 2 min instead of 5 min long and rats received VEH or ANI (160 $\mu$ g/side) immediately after the reactivation phase. ${ }^{* *} P<0.005,{ }^{*} P<0.05$ in Student's $t$-test; $n=10$ per group. (C) Animals $(n=22)$ were treated as in $A$ except that the 5 min reactivation phase was performed $5 \mathrm{~d}$ instead of $1 \mathrm{~d}$ after training and rats received VEH or ANI (160 $\mu \mathrm{g} / \mathrm{side})$ immediately after the reactivation phase. In all cases data are presented as mean ( \pm SEM) of the percentage of time exploring a particular object over the total time of object exploration. ${ }^{* * *} P<0.0005,{ }^{* \star} P<0.005$ in Student's $t$-test; $n=11$ per group.

(Rodriguez-Ortiz et al. 2005). For that reason, we decided to analyze whether inhibition of hippocampal protein synthesis affects the persistence of recognition memory when reactivation happens alongside the incorporation of new information. To do that, on day 1 we exposed rats to two different objects (A and B) for 5 min (Sample phase). On day 2 the animals were exposed for an additional 5 min to one of the objects that had been presented during the sample phase (object A) together with a novel object (object C) and, immediately after that, they received bilateral intra-CA1 infusions of ANI (160 $\mu \mathrm{g} /$ side) or vehicle. Following that, animals were randomly assigned to one out of three experimental groups, and memory retention was tested $24 \mathrm{~h}$ later (Test phase). During the test phase, Group 1 was exposed to object A plus a novel object D; Group 2 was exposed to objects B and D; and Group 3 was left to explore objects C and D (see Fig. 5). As expected, animals that had received vehicle after memory reactivation spent more time exploring the novel object D than any of the other objects during the test phase, reflecting that they remembered object A (Fig. 5; Test phase-Group 1, VEH; $P<0.0005, t_{[10]}=6.82$ ) and object B (Fig. 5; Test phase-Group 2, VEH; $P<0.005, t_{[10]}=3.76$ ), which had been presented on day 1 , and also that they had acquired the memory for object $\mathrm{C}$ during the reactivation phase on day 2 (Fig. 5; Test phase-Group 3, VEH; $\left.P<0.0005, t_{[11]}=7.04\right)$. However, animals that received intra-CA1 ANI right after the reactivation phase spent the same amount of time exploring objects A and D (Fig. 5; Test phase-
Group 1; ANI) and objects C and D (Fig. 5B; Test phase-Group 3; ANI), indicating that ANI hindered retention of the memory for object $\mathrm{A}$ and blocked formation of the memory for object $\mathrm{C}$. Interestingly, the memory for object B (which was not presented during the reactivation phase) was unaffected by intrahippocampal infusion of ANI (Fig. 5; Test phase-Group 2, ANI; $\left.P<0.0005, t_{[8]}=6.47\right)$.

To analyze whether ANI-induced amnesia was temporary, animals were trained and tested as explained above except that the test phase was performed $120 \mathrm{~h}$ instead of $24 \mathrm{~h}$ after reactivation. As shown in Figure 6, the time spanned between reactivation and test sessions had no effect on the amnesia provoked by the post-reactivation administration of ANI, suggesting that this effect was not reversible. Importantly, ANI had no effect on memory retention when given $24 \mathrm{~h}$ after the sample phase in the absence of memory reactivation (Fig. 7).

It is known that contextual cues present during training trials can act as reminders to promote retrieval of a learned experience (Spear 1973; Sara 2000). This suggests that, if salient enough, contextual information alone can reactivate a consolidated trace. Therefore, in order to determine whether hippocampal protein synthesis-dependent reconsolidation of the object recognition trace occurs when contextual information is provided alone, on day 1 animals were exposed for 5 min to objects A and B (Sample phase) and $24 \mathrm{~h}$ later submitted to a contextual reactivation session in the absence of objects. Immediately after 


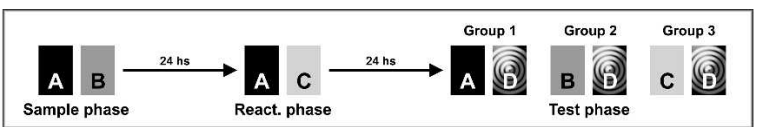

Sample phase
(Day 1)

Group 1
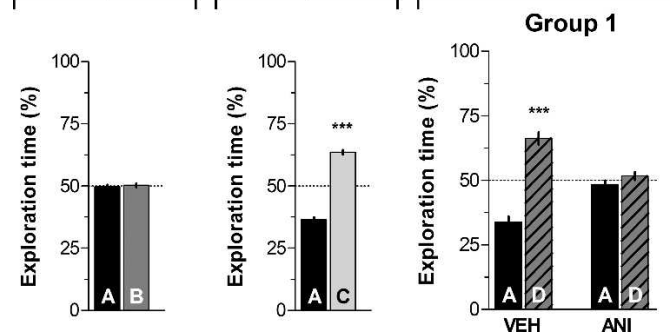

\section{Test phase (Day 3)}

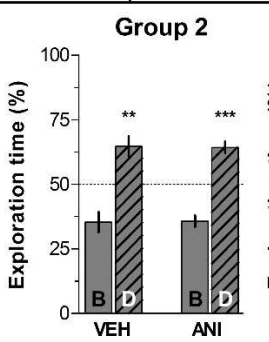

Figure 5. Inhibition of hippocampal protein synthesis after a reactivation session involving exposition to a novel and a familiar object impairs memory of these two objects but does not affect that of a familiar object not presented during the reactivation phase. Rats with infusion cannulae implanted in the CA1 region of the dorsal hippocampus $(n=63)$ were exposed to two objects (A and B) for 5 min (Sample phase; Day 1). Twenty-four hours later the animals were exposed to familiar object A plus a novel object (C) (Reactivation phase; Day 2). Rats were randomly assigned to one out of three different groups and immediately after that received bilateral intra-CA1 infusions of either vehicle (VEH) or anisomycin $(160 \mu \mathrm{g} / \mathrm{side}$; ANI). Twenty-four hours later animals were submitted to a 5 -min-long test phase (Test phase; Day 3) in the presence of different combinations of objects, as follows: (Group 1) Object A + Object D; (Group 2) Object B + Object D; (Group 3) Object C + Object D, where D was a novel object. Note that $\mathrm{ANI}$ impaired retention of the memory for the novel object $C$ and also for the familiar object $A$ (which was presented during the reactivation session) but spared memory for familiar object $B$, to which animals were not exposed during the reactivation phase. Data are presented as mean $( \pm S E M)$ of the percentage of time exploring a particular object over the total time of object exploration. ${ }^{* *} P<0.0005,{ }^{* *} P<0.005$ in Student's $t$-test; $n=9-12$ per group. (Top) Schematic representation of the behavioral protocol used.

that, animals received bilateral intra-CA1 infusions of vehicle or ANI (160 $\mu \mathrm{g} /$ side) and were tested for retention $24 \mathrm{~h}$ later. During the test phase both vehicle and ANI-infused animals spent more time exploring a novel object $\mathrm{D}$ than familiar objects A $\left(P<0.005, t_{[11]}=3.91\right.$ and $P<0.0005, t_{[9]}=7.17$ for VEH- and ANI-treated animals, respectively $)$ or $\mathrm{B}\left(P<0.005, t_{[9]}=4.18\right.$ and

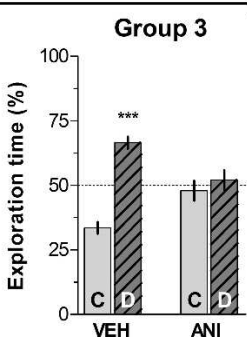

$P<0.0005, t_{[9]}=6.18$ for VEH- and ANItreated animals), suggesting that context alone is not sufficient to reactivate the trace to induce object recognition memory reconsolidation (Fig. 8A). An additional experiment confirmed that the amnesia produced by intra-CA1 ANI is indeed contingent with the presence of both a novel and a familiar object during the reactivation phase. When ANI $(160 \mu \mathrm{g} /$ side) was given into dorsal CA1 immediately after a 5-min pseudoreactivation session (i.e., a behavioral session during which animals were left to explore two objects different from those presented in the sample session), it had no effect at all on the persistence of the original memory (Fig. 8B, Test phase, Groups 1 and 2) but blocked retention of the memory for the two objects introduced during that session (Fig. 8B, Test phase, Groups 3 and 4).

\section{Discussion}

The present study provides evidence for the involvement of the hippocampus in object recognition memory. In particular, our results demonstrate the necessity of hippocampal protein synthesis during a restricted post-training period for the normal consolidation of this type of memory and indicate that, under certain circumstances, retrieval renders the consolidated recognition memory trace again susceptible to inhibition of hippocampal protein synthesis.

It has been previously demonstrated that inhibition of protein synthesis in different memory-relevant areas of the brain impairs memory consolidation in several preparations (Gibbs
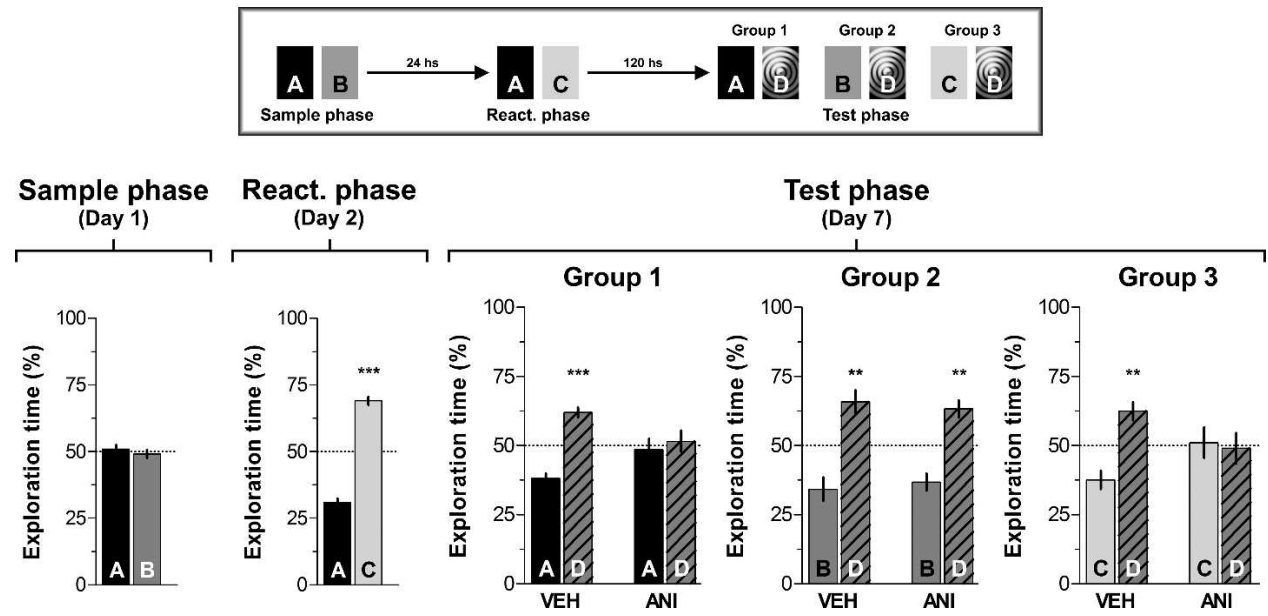

Figure 6. The time elapsed between reactivation and test sessions had no effect on the amnesia caused by the post-reactivation infusion of ANI in the CA1 region of the hippocampus. Rats with infusion cannulae implanted in the CA1 region of the dorsal hippocampus $(n=59)$ were exposed to two objects (A and B) for 5 min (Sample phase; Day 1). Five days later the animals were exposed to familiar object A plus a novel object (C) (Reactivation phase; Day 6). Rats were randomly assigned to one out of three different groups and immediately after that received bilateral intra-CA1 infusions of either vehicle (VEH) or anisomycin $(160 \mathrm{\mu g} / \mathrm{side}$; ANI). Twenty-four hours later animals were submitted to a 5-min-long test phase (Test phase; Day 7) in the presence of different combinations of objects, as follows: (Group 1) Object A + Object D; (Group 2) Object B + Object D; (Group 3) Object C + Object $D$, where D was a novel object. Note that ANI impaired retention of the memory for the novel object C and also for the familiar object A (which was presented during the reactivation session) but spared memory for familiar object $\mathrm{B}$, to which animals were not exposed during the reactivation phase. Data are presented as mean $\left( \pm\right.$ SEM) of the percentage of time exploring a particular object over the total time of object exploration. ${ }^{* * *} P<0.0005$, ${ }^{* *} P<0.005$ in Student's $t$-test; $n=9-10$ per group. (Top) Schematic representation of the behavioral protocol used. 

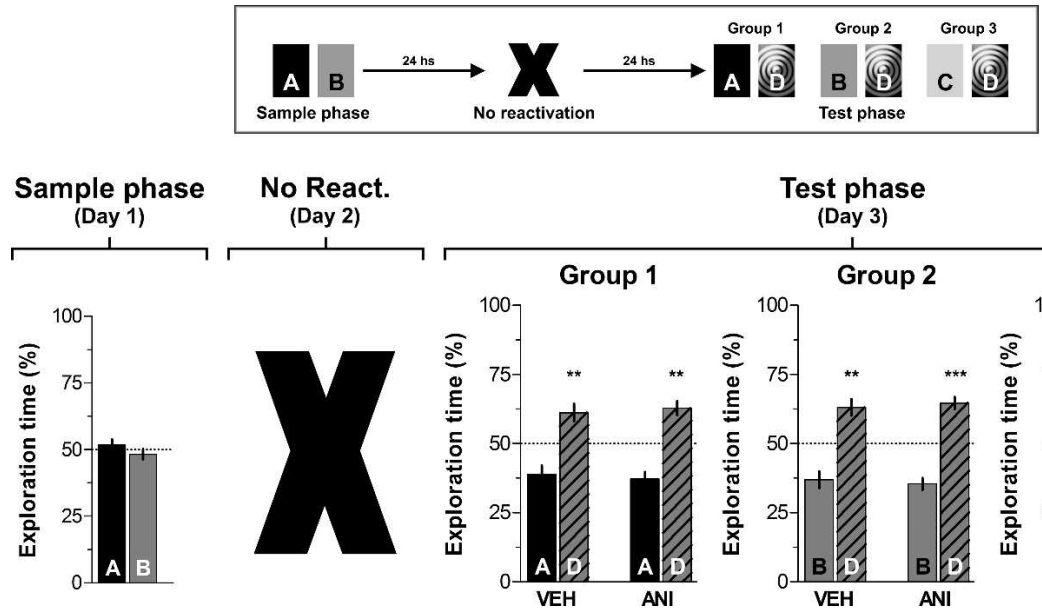

Test phase

(Day 3)
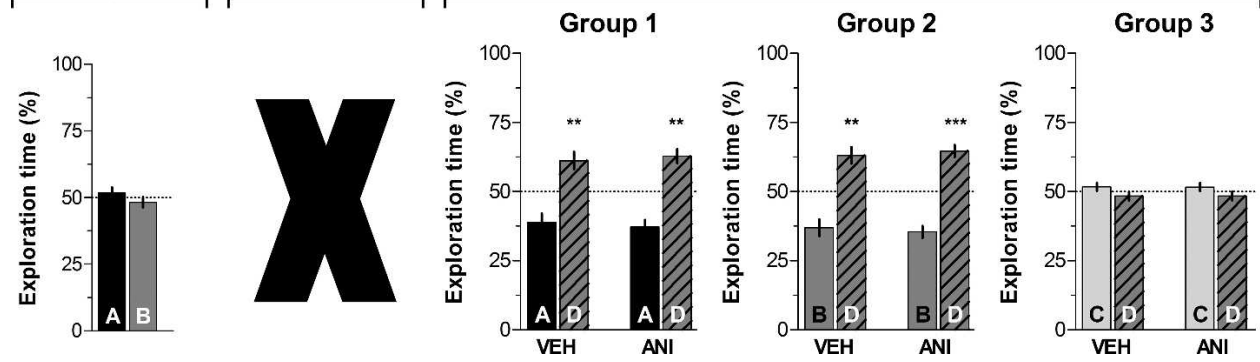

Figure 7. Inhibition of hippocampal protein synthesis $24 \mathrm{~h}$ after training in the absence of a behaviorally relevant event does not affect retention of object recognition memory. Rats with infusion cannulae implanted in the CA1 region of the dorsal hippocampus $(n=60)$ were exposed to two objects (A and B) for 5 min (Sample phase; Day 1). Twenty-four hours later animals were randomly assigned to one out of three different groups, were given bilateral intra-CA1 infusions of either vehicle (VEH) or anisomycin $(160 \mu \mathrm{g} / \mathrm{side}$; ANI), and after that they were returned to their home cages without receiving any specific stimuli. Twenty-four hours later animals were submitted to a 5-min-long test phase (Test phase; Day 3) in the presence of different combinations of objects, as follows: (Group 1) Object A + Object D; (Group 2) Object B + Object D; (Group 3) Object C + Object D, where C and D were novel objects. Data are presented as mean ( \pm SEM) of the percentage of time exploring a particular object over the total time of object exploration. ${ }^{* * *} P<0.0005,{ }^{* *} p<0.005$ in Student's $t$-test; $n=10$ per group. (Top) Schematic representation of the behavioral protocol used.

and Ng 1978; Barraco et al. 1981; Staubli et al. 1985; Crow and Forrester 1990; Ramirez et al. 1998; Wustenberg et al. 1998; Epstein et al. 2003; Ezzeddine and Glanzman 2003; Rossato et al. 2006). Most findings indicate the existence of a critical time window for protein synthesis during or immediately after training, and several reports also point to a second phase of sensitivity of memory to protein synthesis inhibition 3-6 $\mathrm{h}$ post-training (Grecksch and Matthies 1980; Freeman et al. 1995; Igaz et al. 2002). Here we showed that bilateral infusions of ANI into the CA1 region of the dorsal hippocampus immediately or $180 \mathrm{~min}$ after the sample phase significantly impaired object recognition memory. Importantly, the effect of ANI was not observed when this drug was given into CA1 360 min post-training, indicating that the induced amnesia was due to blockade of the consolidation process and not to a permanent insult on hippocampal functionality or to impaired performance (Fig. 1). This was confirmed by experiments showing that, post-training, intra-CA1 ANI did not affect retention of short-term recognition memory (Fig. 2), and by others demonstrating that: (1) infusion of this drug $24 \mathrm{~h}$ pre-test did not modify exploration of an open field arena or the animals' behavior in an elevated plus-maze (Table 1); (2) animals that had received intrahippocampal ANI $24 \mathrm{~h}$ before the respective behavioral session normally acquired a spatial preference in the water maze and an aversive conditioned response in the inhibitory avoidance training box (Fig. 3), two learning paradigms that involve different memory types known to require the physiological integrity of the hippocampal formation.

It has been assumed that some cortical regions, particularly the perirhinal cortex, may have a more prominent participation than the hippocampus in the processing of object recognition memory (Mumby 2001; Winters et al. 2006). However, it was recently shown that exposure to two novel objects as well as re-exposure to these same objects $24 \mathrm{~h}$ later increases ERK phosphorylation in the dentate gyrus/CA1 region, suggesting that consolidation and maybe also retrieval of object recognition memory involves activation of the hippocampal formation (Kelly et al. 2003). Notwithstanding this and despite the fact that the hippocampus is central for reconsolidation of several memory types (Sara 2000; Myers and Davis 2002; Dudai 2006), and also that the reconsolidation hypothesis posits that some of the molecular events necessary for consolidation are re-engaged after retrieval for reconsolidation of the reactivated trace (Debiec et al. 2002; Myers and Davis 2002), we failed to detect any effect of ANI on the persistence of recognition memory when this drug was given into dorsal CA1 after a reactivation session involving re-exposure to two familiar objects (Fig. 4A). The lack of effect of ANI was independent of the length of the reactivation session (Fig. 4B) and of the age of the object recognition trace (Fig. 4C), two factors repeatedly reported to affect the likelihood of reconsolidation (Milekic and Alberini 2002; Pedreira and Maldonado 2003; Suzuki et al. 2004; Boccia et al. 2006).

This negative result is probably due to the fact that the procedure we employed to reactivate the recognition trace acted not only as a retrieval session but also as a second training session during which no novel information was available. Recent behavioral and biochemical analyses indicate that the role played by the hippocampus during recognition is limited to the detection of novelty and to the identification of changes in spatial configuration (Wan et al. 1999; Viola et al. 2000; Hammond et al. 2004; Winograd and Viola 2004; Aggleton and Brown 2005; Moncada and Viola 2006). Indeed, it has been reported that hippocampal damage impairs memory for contextual and spatial aspects of an experience, whereas memory for objects that were part of the same experience are left relatively intact (Mumby et al. 2002a,b). Other brain regions, particularly the prefrontal cortex, seem to be required for discriminating the relative recency of previously encountered stimuli and to modulate retrieval of the information necessary for temporal order memory (Rainer and Miller 2000; Xiang and Brown 2004; Hannesson et al. 2004a,b). In this respect, using a memory reactivation protocol involving re-exposure to familiar objects, it has been recently shown that the infusion of ANI into the prefrontal cortex blocks reconsolidation of object recognition memory (Akirav and Maroun 2006).

Ample evidence has established that memories become labile after retrieval and require another phase of protein synthesis to be maintained (for recent review, see Dudai 2006), but there is no consensus as to whether reconsolidation is just a repetition of consolidation or a distinct process (Alberini 2005). Although 
A
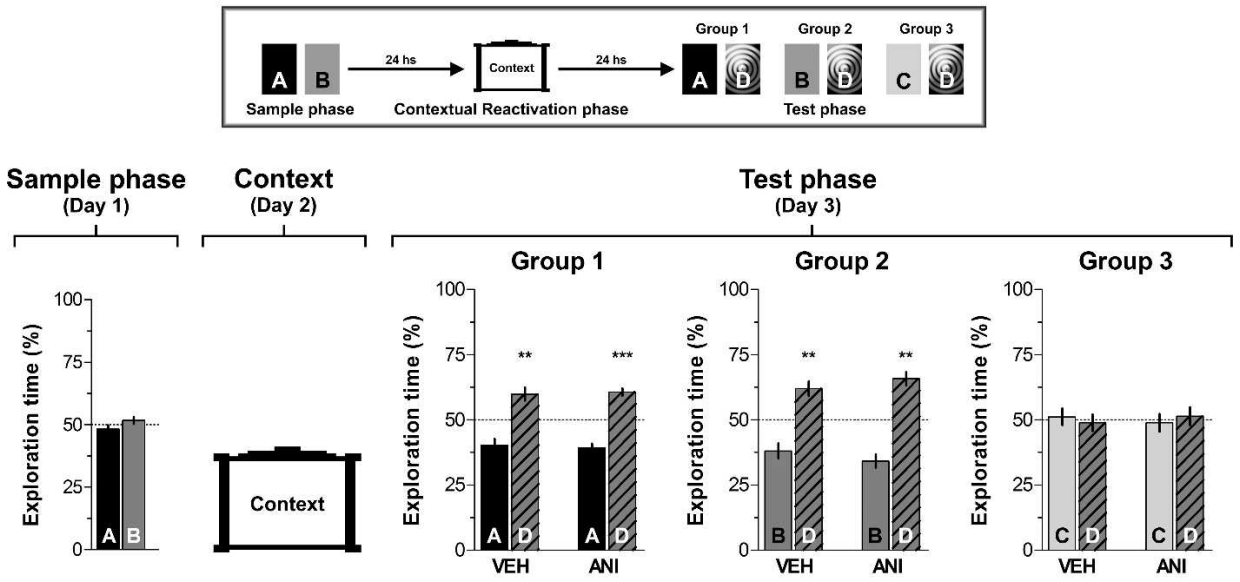

B
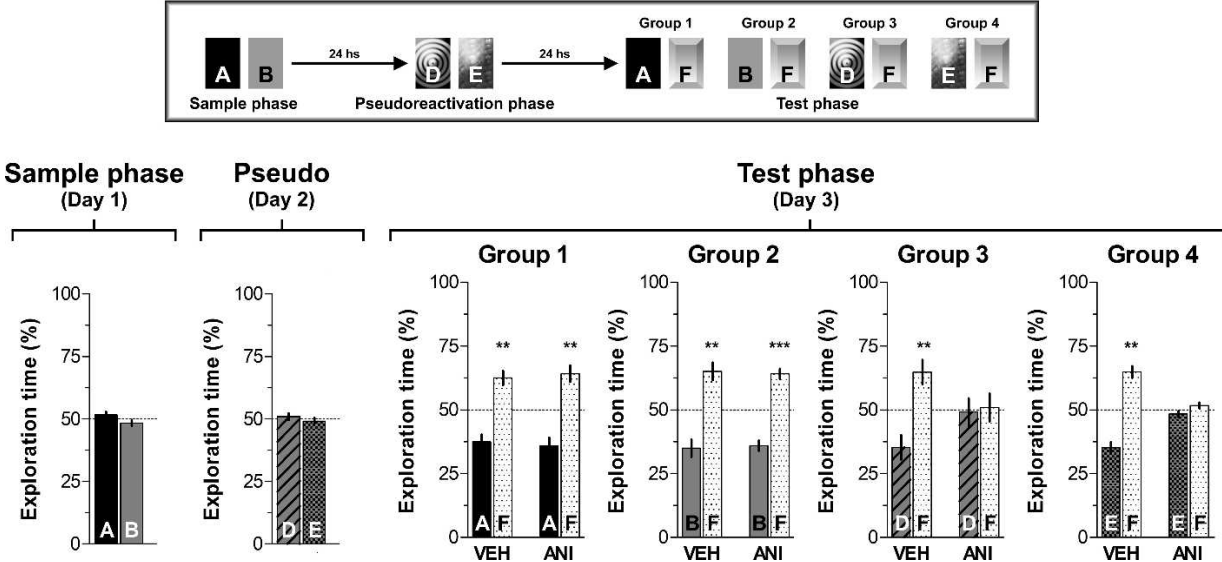

Figure 8. Inhibition of hippocampal protein synthesis after exposure to the training box context alone or following a pseudoreactivation session involving exposition to two novel objects does not affect the original recognition memory. ( $A$ ) Rats with infusion cannulae implanted in the CA1 region of the dorsal hippocampus $(n=62)$ were exposed to two objects (A and B) for 5 min (Sample phase, Day 1 ). Twenty-four hours later the animals were left to freely explore the open field arena in the absence (Contextual Reactivation phase; Day 2). Rats were randomly assigned to one out of three different groups and immediately after that received bilateral intra-CA1 infusions of either vehicle (VEH) or anisomycin (160 $\mu$ g/side; ANI). Twenty-four hours later animals were submitted to a 5-min-long test phase (Test phase; Day 3 ) in the presence of different combinations of objects, as follows: (Group 1) Object A + Object D; (Group 2) Object B + Object D; (Group 3) Object C + Object D, where C and D were novel objects. ***P<0.0005, $* * P<0.005$ in Student's t-test; $n=10-12$ per group. (Top) Schematic representation of the behavioral protocol used. (B) Rats with infusion cannulae implanted in the CA1 region of the dorsal hippocampus $(n=77)$ were exposed to two objects $(A$ and B) for 5 min (Sample phase; Day 1$)$. Twenty-four hours later the animals were exposed to two novel objects D and E (Pseudoreactivation phase; Day 2). Rats were randomly assigned to one out of four different groups and immediately after that received bilateral intra-CA1 infusions of either vehicle (VEH) or anisomycin (160 $\mu$ g/side; ANI). Twenty-four hours later animals were submitted to a 5-min-long test phase (Test phase; Day 3) in the presence of different combinations of objects, as follows: (Group 1) Object A + Object F; (Group 2) Object B + Object F; (Group 3) Object D + Object F; (Group 4) Object E + Object F, where F was a novel object. Note that ANI impaired retention of the memory for the novel objects $D$ and $E$ (which were presented during the Pseudoreactivation session) but spared memory for familiar objects $A$ and $B$, to which animals were only exposed during the sample phase. Data are presented as mean ( \pm SEM) of the percentage of time exploring a particular object over the total time of object exploration. ${ }^{* * *} P<0.0005,{ }^{* *} P<0.005$ in Student's $t$-test; $n=8-10$ per group. (Top) Schematic representation of the behavioral protocol used.

some of the implications of the reconsolidation hypothesis fit neatly in the active-inactive memory model proposed by Lewis (1979) to explain cue-dependent amnesia (Lewis et al. 1972; Bregman et al. 1976), several studies suggest that many of the molecular events underlying consolidation are not recapitulated every time memory is retrieved. In fact, it has been proposed that the purpose of reconsolidation is not merely to rebuild a trace made vulnerable after reactivation but to integrate a new experience with a previously consolidated memory (Nader et al. 2000b; Sara 2000; Rodriguez-Ortiz et al. 2005; Rossato et al. 2006). If this is the role of reconsolidation, and considering that during object recognition the hippocampus acts mainly as a novelty detector, then it would be feasible to suppose that the hippocampus is necessary to modify a consolidated recognition trace after the animal detects a difference between what it expected and what actually occurred (Pedreira et al. 2004). To test this hypothesis, we evaluated whether inhibition of hippocampal protein synthesis after a reactivation session involving presentation of a familiar and a novel object had any effect on further retention. We reasoned that if the hippocampus was really involved in recognition memory reconsolidation, then the post-reactivation infusion of ANI should impair future recognition of the object that had been presented during both the sample and the reactivation phase but leave intact the memory of the familiar object presented only

\section{Learning \& Memory}

www.learnmem.org 
during the sample phase. As can be seen in Figure 5, this was exactly what happened. Moreover, ANI also blocked retention of the memory for the novel object introduced during the reactivation phase. The amnesic effect of ANI was independent of the time spanned between reactivation and test phases (Fig. 6) and was not observed in the absence of reactivation (Fig. 7) or when the objects presented during the reactivation phase were both novel (Fig. 8B). ANI also had no effect on memory persistence when given into CA1 after a contextual reactivation session in the absence of any stimulus object (Fig. 8A). These control experiments have important implications. Firstly, they indicate that the amnesic effect of post-retrieval ANI is due to disruption of the object recognition memory trace and not just to a temporary performance effect. Secondly, they demonstrate that the participation of the hippocampus in object recognition memory reconsolidation is associated with reactivation of the recognition trace in the presence of a particular set of retrieval cues involving both novel and familiar elements. Thirdly, they suggest that exposure to the context alone does not reactivate the object recognition trace effectively, at least not to the point of inducing hippocampal-dependent reconsolidation. This lack of effect may be ascribed to the fact that animals were pre-habituated to the open field arena before training in the object recognition task and, therefore, the importance of the context as a predictor of the occurrence of a given set of objects and its ability to prompt retrieval was greatly diminished.

In conclusion, our results support the hypothesis that hippocampal protein synthesis is required for consolidation of object recognition memory and strengthen the notion that the recognition trace becomes labile after retrieval, and to be maintained it requires the occurrence of a hippocampaldependent reconsolidation phase. Others have shown that different cortical regions are required for reconsolidation of object recognition memory when retrieval was induced by familiar objects. Specifically, Kelly and coworkers (2003) have shown that the intracerebroventricular infusion of an inhibitor of the ERK1/2 signaling pathway blocks persistence of the recognition trace, while Akirav and Maroun (2006) showed the participation of the ventro-medial prefrontal cortex in this process. Moreover, Bozon et al. (2003) reported that zif286 mutant mice are unable to further retrieve the recognition trace after reactivation.

Our results indicate that the hippocampus only is engaged in reconsolidation of the recognition trace when retrieval has occurred concomitantly with the acquisition of information about a new object but not when the original memory is fully reactivated during a second training session. Taken together with the above-mentioned reports (Bozon et al. 2003; Kelly et al. 2003; Akirav and Maroun 2006), our experiments suggest that, as happens during consolidation (Izquierdo et al. 2006), reconsolidation also entails the participation of different areas of the brain, maybe processing different aspects of the mnemonic trace or allowing incorporation of both new and previously consolidated information into the engram. It must be recognized though, that despite the fact that our results can unquestionably be interpreted as due to the effect of ANI on reconsolidation, we cannot irrefutably exclude the possibility that during partial reactivation of the original trace in the presence of a familiar and a novel object a new memory has formed and that the amnesic effect of intra-CA1 ANI we observed was actually due to a blocking action on consolidation of this new trace rather than on reconsolidation of the original memory. Results from control experiments argue against this last prospect but, at present, it is impossible to conclusively discriminate between these two possibilities. At any rate, the biological significance of the processes described above would remain unaltered.

\section{Materials and Methods}

\section{Subjects, surgery, and drug infusion}

The subjects were 630 experimentally naive male Wistar rats (3-mo-old, 250-280 g) raised in our own facilities. They were housed four to a cage and kept with continuous access to food and water under a 12-h light/12-h dark cycle, with lights on at 7:00 a.m. The animal's room temperature was maintained at 22$24^{\circ} \mathrm{C}$. To implant them with indwelling cannulae, rats were deeply anesthetized with thiopental (30-50 mg/Kg, i.p.), and 27gauge cannulae were stereotaxically aimed to the CA1 region of the dorsal hippocampus, in accordance with coordinates (A - 4.0 $\mathrm{L} \pm 3.0, \mathrm{~V}$ 1.8) taken from the atlas of Paxinos and Watson (1986). Animals were allowed to recover from surgery for $4 \mathrm{~d}$ before submitting them to any other procedure.

At the time of drug delivery, 30-gauge infusion cannulae were tightly fitted into the guides. Infusions $(0.8 \mu \mathrm{L} /$ side $)$ were carried out over $90 \mathrm{sec}$, and the infusion cannulae were left in place for an additional $60 \mathrm{sec}$ to minimize backflow. Cannulae placement was verified postmortem: $2-4 \mathrm{~h}$ after the last behavioral test, $0.8 \mu \mathrm{L}$ of a $4 \%$ methylene-blue solution was infused as described above and the extension of the dye $30 \mathrm{~min}$ thereafter was taken as indicative of the presumable diffusion of the vehicle or drug previously given to each animal. Only data from animals with correct cannulae implants were included in statistical analyses (591 animals; $94 \%$ of the total utilized). All procedures involving rats were conducted in accordance with the "Principles of Laboratory Animal Care" (NIH publication no. 85-23, revised 1996). Every effort was made to reduce the number of animals used and to minimize their suffering.

\section{Drug}

Anisomycin (Sigma) was dissolved in $1 \mathrm{M} \mathrm{HCl}$, diluted in saline, the $\mathrm{pH}$ was adjusted to $7.2-7.5$ with $\mathrm{NaOH}$, and the solution was kept protected from light at $-20^{\circ} \mathrm{C}$. Immediately before use, aliquots were thawed and diluted to working concentration with saline.

\section{Object recognition task}

If rats are presented familiar and novel objects, they will direct more exploration at the novel objects. This typical behavior was exploited to design a behavioral paradigm known as object recognition task, which has been previously employed to successfully evaluate recognition memory (Ennaceur and Delacour 1988). The object recognition task was conducted in an open field arena $(50 \times 50 \times 50 \mathrm{~cm})$ built of polyvinyl chloride plastic, plywood, and transparent acrylic. Before the experiment was performed, all the animals were habituated to the experimental arena by allowing them to freely explore it $20 \mathrm{~min}$ per day for $4 \mathrm{~d}$ in the absence of stimulus objects. The stimulus objects were made of metal, glass, or glazed ceramic. There were several copies of each object, which were used interchangeably. Glued to the base of each object was a rounded piece of Velcro, which was used to fix the object to the arena's floor. The role (familiar or novel) as well as the relative position of the two stimulus objects were counterbalanced and randomly permuted for each experimental animal. The open field arena and the stimulus objects were cleaned thoroughly between trials to ensure the absence of olfactory cues. Exploration was defined as sniffing or touching the stimulus object with the nose and/or forepaws. Sitting on or turning around the objects was not considered exploratory behavior. A video camera was positioned over the arena, and the rats' behavior was videotaped for later analysis. The time spent exploring each object was recorded by an observer blind to the treatment and expressed as a percentage of the total exploration time in seconds.

\section{Recognition memory consolidation protocol}

On day 1 (sample phase), rats were placed in the open field containing two different objects and left to freely explore them for $5 \mathrm{~min}$. The test phase was performed either $180 \mathrm{~min}$ (to analyze 
short-term memory) or $24 \mathrm{~h}$ after the sample phase (to evaluate long-term memory). In the test phase one of the objects was randomly exchanged for a novel object, and rats were reintroduced into the open field for an additional 5-min period. The protein synthesis inhibitor anisomycin (ANI; $160 \mu \mathrm{g}$ ) or vehicle was bilaterally infused into the CA1 region of the dorsal hippocampus $(0.8 \mu \mathrm{L} /$ side $)$ at different times after the sample phase. Student's $t$-test was used to analyze the data.

\section{Recognition memory reactivation protocol}

On day 1 (sample phase), rats were exposed to two different objects for $5 \mathrm{~min}$, as described above. Twenty-four or $120 \mathrm{~h}$ later (reactivation phase), rats were exposed to the same two sample objects for 1 or 5 min to reactivate the memory trace. Immediately after the reactivation phase, the animals received bilateral intra-CA1 infusions ( $0.8 \mu \mathrm{L} /$ side) of vehicle or ANI (160 $\mu \mathrm{g} / \mathrm{side})$. Twenty-four hours later (test phase), rats were placed again in the open field, in which one of the objects was exchanged for a novel object, and the time spent exploring each object was recorded. Student's $t$-test was used to analyze the data.

\section{Recognition memory update protocol}

On day 1 (sample phase), rats were exposed to two different objects (A and $B$ ) for 5 min. Twenty-four hours later (reactivation phase), one of the objects was randomly exchanged for a novel one (object C), and rats were placed again in the open field for $5 \mathrm{~min}$. Immediately after the reactivation phase, the animals received bilateral intra-CA1 infusions $(0.8 \mu \mathrm{L} /$ side $)$ of vehicle or ANI (160 $\mu \mathrm{g} / \mathrm{side})$. Twenty-four hours later (test phase), rats were randomly assigned to three different groups. Group 1 was reintroduced into the open field and presented with one of the objects that had been presented during the sample phase (object A) plus a novel object (object D). Group 2 was treated as group 1 except that the familiar object that was presented together with the novel object D was object B. Group 3 was presented to novel object $\mathrm{D}$ plus the object that had been introduced during the reactivation phase (i.e., object $\mathrm{C}$ ). Student's $t$-test was used to analyze the data.

\section{Training in the spatial version of the Morris water maze}

The water maze was a black circular pool (200-cm in diameter) conceptually divided in four equal imaginary quadrants for the purpose of data analysis. The water temperature was $21-23^{\circ} \mathrm{C}$. Two centimeters beneath the surface of the water and hidden from the rat's view was a black circular platform $(15 \mathrm{~cm}$ in diameter). It had a rough surface, which allowed rats to climb onto it easily. The swimming path of the animals was recorded using a video camera mounted above the center of the pool and analyzed using a video tracking and analysis system. The water maze was located in a well-lit white room with several posters and other distal visual stimuli hanging on the walls to provide spatial cues. A curtain separated the water maze room from the room where the computer was set up and where the animals were temporarily housed during the behavioral sessions. Training in the hidden platform (spatial) version of the MWM was carried out during five consecutive days as previously described (Rossato et al. 2006). On each day, rats received eight consecutive training trials during which the hidden platform was kept in a constant location. A different starting location was used on each trial, which consisted of a swim followed by a 30 -sec platform sit. Any rat that did not find the platform within $60 \mathrm{sec}$ was guided to it by the experimenter. The intertrial interval (ITI) was 30 sec. During the ITI, rats were carefully dried with a towel by the experimenter. Memory retention was evaluated in a 60 -sec probe trial carried out in the absence of the escape platform $24 \mathrm{~h}$ after the last training session. Student's $t$-test was used to analyze the data.

\section{Training in one-trial step-down inhibitory avoidance}

Rats were trained in a one-trial, step-down inhibitory avoidance task, a widely used model of fear-motivated, hippocampaldependent learning, as previously described (Bevilaqua et al.
2005). The training apparatus was a $50 \times 25 \times 25-\mathrm{cm}$ Plexiglas box with a 5 -cm-high, 8 -cm-wide, and 25 -cm-long platform on the left end of a series of bronze bars that made up the floor of the box. For training, animals were gently placed on the platform facing the left rear corner of the training box. When they stepped down and placed their four paws on the grid, they received a 2-sec, 0.5-mA scrambled footshock. Memory retention was evaluated in a non-reinforced test session carried out at $24 \mathrm{~h}$ after training. Data were analyzed using the Mann-Whitney U-test.

\section{Acknowledgments}

This work was supported by research grants from the National Research Council of Brazil (CNPq) through the National Program for Nuclei of Excellence (PRONEX) and from the National Agency of Scientific and Technological Promotion of Argentina (ANPCyT).

\section{References}

Aggleton, J.P. and Brown, M.W. 2005. Contrasting hippocampal and perirhinal cortex function using immediate early gene imaging. Q. J. Exp. Psychol. B 58: 218-233.

Akirav, I. and Maroun, M. 2006. Ventromedial prefrontal cortex is obligatory for consolidation and reconsolidation of object recognition memory. Cereb. Cortex 16: 1759-1765.

Alberini, C.M. 2005. Mechanisms of memory stabilization: Are consolidation and reconsolidation similar or distinct processes? Trends Neurosci. 28: 51-56.

Barraco, D.A., Lovell, K.L., and Eisenstein, E.M. 1981. Effects of cycloheximide and puromycin on learning and retention in the cockroach, P. americana. Pharmacol. Biochem. Behav. 15: 489-494.

Bevilaqua, L.R., Medina, J.H., Izquierdo, I., and Cammarota, M. 2005. Memory consolidation induces $N$-methyl-D-aspartic acid-receptorand $\mathrm{Ca}^{2+} /$ calmodulin-dependent protein kinase II-dependent modifications in $\alpha$-amino-3-hydroxy-5-methylisoxazole-4-propionic acid receptor properties. Neuroscience 136: 397-403.

Biedenkapp, J.C. and Rudy, J.W. 2004. Context memories and reactivation: Constraints on the reconsolidation hypothesis. Behav. Neurosci. 118: 956-964.

Boccia, M.M., Blake, M.G., Acosta, G.B., and Baratti, C.M. 2006. Post-retrieval effects of icv infusions of hemicholinium in mice are dependent on the age of the original memory. Learn. Mem. 13: $376-381$

Bozon, B., Davis, S., and Laroche, S. 2003. A requirement for the immediate early gene zif268 in reconsolidation of recognition memory after retrieval. Neuron 40: 695-701.

Bregman, N., Nicholas, T., and Lewis, D.J. 1976. Cue-dependent amnesia: Permanence and memory return. Physiol. Behav. 17: 267270.

Cammarota, M., Bevilaqua, L.R., Kerr, D., Medina, J.H., and Izquierdo, I. 2003. Inhibition of mRNA and protein synthesis in the CA1 region of the dorsal hippocampus blocks reinstallment of an extinguished conditioned fear response. J. Neurosci. 23: 737-741.

Cammarota, M., Bevilaqua, L.R., Medina, J.H., and Izquierdo, I. 2004. Retrieval does not induce reconsolidation of inhibitory avoidance memory. Learn. Mem. 11: 572-578.

Clark, R.E., Zola, S.M., and Squire, L.R. 2000. Impaired recognition memory in rats after damage to the hippocampus. J. Neurosci. 20: $8853-8860$.

Crow, T. and Forrester, J. 1990. Inhibition of protein synthesis blocks long-term enhancement of generator potentials produced by one-trial in vivo conditioning in Hermissenda. Proc. Natl. Acad. Sci. 87: 4490-4494.

Dawson, R.G. and McGaugh, J.L. 1969. Electroconvulsive shock effects on a reactivated memory trace: Further examination. Science 166: $525-527$

Debiec, J., LeDoux, J.E., and Nader, K. 2002. Cellular and systems reconsolidation in the hippocampus. Neuron 36: 527-538.

Dudai, Y. 2006. Reconsolidation: The advantage of being refocused. Curr. Opin. Neurobiol. 16: 174-178.

Eisenberg, M. and Dudai, Y. 2004. Reconsolidation of fresh, remote, and extinguished fear memory in Medaka: Old fears don't die. Eur. J. Neurosci. 20: 3397-3403.

Eisenberg, M., Kobilo, T., Berman, D.E., and Dudai, Y. 2003. Stability of retrieved memory: Inverse correlation with trace dominance. Science 301: 1102-1104.

Ennaceur, A. and Aggleton, J.P. 1994. Spontaneous recognition of object configurations in rats: Effects of fornix lesions. Exp. Brain Res. 100: 85-92.

\section{Learning \& Memory}


Ennaceur, A. and Delacour, J. 1988. A new one-trial test for neurobiological studies of memory in rats. 1: Behavioral data. Behav. Brain Res. 31: 47-59.

Ennaceur, A., Neave, N., and Aggleton, J.P. 1996. Neurotoxic lesions of the perirhinal cortex do not mimic the behavioural effects of fornix transection in the rat. Behav. Brain Res. 80: 9-25.

Ennaceur, A., Neave, N., and Aggleton, J.P. 1997. Spontaneous object recognition and object location memory in rats: The effects of lesions in the cingulate cortices, the medial prefrontal cortex, the cingulum bundle and the fornix. Exp. Brain Res. 113: 509-519.

Epstein, H.T., Child, F.M., Kuzirian, A.M., and Alkon, D.L. 2003. Time windows for effects of protein synthesis inhibitors on Pavlovian conditioning in Hermissenda: Behavioral aspects. Neurobiol. Learn. Mem. 79: 127-131.

Ezzeddine, Y. and Glanzman, D.L. 2003. Prolonged habituation of the gill-withdrawal reflex in Aplysia depends on protein synthesis, protein phosphatase activity, and postsynaptic glutamate receptors. J. Neurosci. 23: 9585-9594.

Freeman, F.M., Rose, S.P., and Scholey, A.B. 1995. Two time windows of anisomycin-induced amnesia for passive avoidance training in the day-old chick. Neurobiol. Learn. Mem. 63: 291-295.

Gainutdinova, T.H., Tagirova, R.R., Ismailova, A.I., Muranova, L.N., Samarova, E.I., Gainutdinov, K.L., and Balaban, P.M. 2005. Reconsolidation of a context long-term memory in the terrestrial snail requires protein synthesis. Learn. Mem. 12: 620-625.

Gaskin, S., Tremblay, A., and Mumby, D.G. 2003. Retrograde and anterograde object recognition in rats with hippocampal lesions. Hippocampus 13: 962-969.

Gibbs, M.E. and Ng, K.T. 1978. Memory formation for an appetitive visual discrimination task in young chicks. Pharmacol. Biochem. Behav. 8: 271-276.

Grecksch, G. and Matthies, H. 1980. Two sensitive periods for the amnesic effect of anisomycin. Pharmacol. Biochem. Behav. 12: 663-665.

Hammond, R.S., Tull, L.E., and Stackman, R.W. 2004. On the delay-dependent involvement of the hippocampus in object recognition memory. Neurobiol. Learn. Mem. 82: 26-34.

Hannesson, D.K., Howland, J.G., and Phillips, A.G. 2004a. Interaction between perirhinal and medial prefrontal cortex is required for temporal order but not recognition memory for objects in rats. J. Neurosci. 24: 4596-4604.

Hannesson, D.K., Vacca, G., Howland, J.G., and Phillips, A.G. 2004b. Medial prefrontal cortex is involved in spatial temporal order memory but not spatial recognition memory in tests relying on spontaneous exploration in rats. Behav. Brain Res. 153: 273-285.

Hernandez, P.J. and Kelley, A.E. 2004. Long-term memory for instrumental responses does not undergo protein synthesis-dependent reconsolidation upon retrieval. Learn. Mem. 11: $748-754$

Igaz, L.M., Vianna, M.R., Medina, J.H., and Izquierdo, I. 2002. Two time periods of hippocampal RNA synthesis are required for memory consolidation of fear-motivated learning. J. Neurosci. 22: 6781-6789.

Inda, M.C., Delgado-Garcia, J.M., and Carrion, A.M. 2005. Acquisition, consolidation, reconsolidation, and extinction of eyelid conditioning responses require de novo protein synthesis. J. Neurosci. 25: $2070-2080$.

Izquierdo, I., Bevilaqua, L.R., Rossato, J.I., Bonini, J.S., Medina, J.H., and Cammarota, M. 2006. Different molecular cascades in different sites of the brain control memory consolidation. Trends Neurosci. 29: 496-505.

Judge, M.E. and Quartermain, D. 1982. Characteristics of retrograde amnesia following reactivation of memory in mice. Physiol. Behav. 28: 585-590.

Kelly, A., Laroche, S., and Davis, S. 2003. Activation of mitogen-activated protein kinase/extracellular signal-regulated kinase in hippocampal circuitry is required for consolidation and reconsolidation of recognition memory. J. Neurosci. 12: 5354-5360.

Kida, S., Josselyn, S.A., de Ortiz, S.P., Kogan, J.H., Chevere, I., Masushige, S., and Silva, A.J. 2002. CREB required for the stability of new and reactivated fear memories. Nat. Neurosci. 5: 348-355.

Lattal, K.M. and Abel, T. 2004. Behavioral impairments caused by injections of the protein synthesis inhibitor anisomycin after contextual retrieval reverse with time. Proc. Natl. Acad. Sci. 101: $4667-4672$.

Lee, J.L., Everitt, B.J., and Thomas, K.L. 2004. Independent cellular processes for hippocampal memory consolidation and reconsolidation. Science 304: 839-843.

Lewis, D.J. 1979. Psychobiology of active and inactive memory. Psychol. Bull. 86: 1054-1083.

Lewis, D.J., Bregman, N.J., and Mahan, J.J. 1972. Cue-dependent amnesia in rats. J. Comp. Physiol. Psychol. 81: 243-247.

Logothetis, N.K. and Sheinberg, D.L. 1996. Visual object recognition.
Annu. Rev. Neurosci. 19: 577-621.

Mactutus, C.F., Riccio, D.C., and Ferek, J.M. 1979. Retrograde amnesia for old (reactivated) memory: Some anomalous characteristics. Science 204: 1319-1320.

McGaugh, J.L. 1966. Time-dependent processes in memory storage. Science 153: 1351-1358.

Merlo, E., Freudenthal, R., Maldonado, H., and Romano, A. 2005. Activation of the transcription factor NF- $\mathrm{B}$ by retrieval is required for long-term memory reconsolidation. Learn. Mem. 12: 23-29.

Milekic, M.H. and Alberini, C.M. 2002. Temporally graded requirement for protein synthesis following memory reactivation. Neuron 36: $521-525$.

Misanin, J.R., Miller, R.R., and Lewis, D.J. 1968. Retrograde amnesia produced by electroconvulsive shock after reactivation of a consolidated memory trace. Science 160: 554-555.

Moncada, D. and Viola, H. 2006. Phosphorylation state of CREB in the rat hippocampus: A molecular switch between spatial novelty and spatial familiarity? Neurobiol. Learn. Mem. 86: 9-18.

Mumby, D.G. 2001. Perspectives on object-recognition memory following hippocampal damage: Lessons from studies in rats. Behav. Brain Res. 127: 159-181.

Mumby, D.G., Gaskin, S., Glenn, M.J., Schramek, T.E., and Lehmann, H. 2002a. Hippocampal damage and exploratory preferences in rats: Memory for objects, places, and contexts. Learn. Mem. 9: 49-57.

Mumby, D.G., Glenn, M.J., Nesbitt, C., and Kyriazis, D.A. 2002b. Dissociation in retrograde memory for object discriminations and object recognition in rats with perirhinal cortex damage. Behav. Brain Res. 132: 215-226.

Myers, K.M. and Davis, M. 2002. Systems-level reconsolidation: Reengagement of the hippocampus with memory reactivation. Neuron 36: 340-343.

Nader, K. 2003. Memory traces unbound. Trends Neurosci. 26: 65-72.

Nader, K., Schafe, G.E., and LeDoux, J.E. 2000a. Fear memories require protein synthesis in the amygdala for reconsolidation after retrieval. Nature 406: 722-726.

Nader, K., Schafe, G.E., and LeDoux, J.E. 2000b. The labile nature of consolidation theory. Nat. Rev. Neurosci. 1: 216-219.

Paxinos, G. and Watson, C. 1986 The rat brain in stereotaxic coordinates. Academic Press, San Diego.

Pedreira, M.E. and Maldonado, H. 2003. Protein synthesis subserves reconsolidation or extinction depending on reminder duration. Neuron 38: 863-869.

Pedreira, M.E., Perez-Cuesta, L.M., and Maldonado, H. 2002. Reactivation and reconsolidation of long-term memory in the crab Chasmagnathus: Protein synthesis requirement and mediation by NMDA-type glutamatergic receptors. J. Neurosci. 22: 8305-8311.

Pedreira, M.E., Perez-Cuesta, L.M., and Maldonado, H. 2004. Mismatch between what is expected and what actually occurs triggers memory reconsolidation or extinction. Learn. Mem. 11: 579-585.

Power, A.E., Berlau, D.J., McGaugh, J.L., and Steward, O. 2006. Anisomycin infused into the hippocampus fails to block "reconsolidation" but impairs extinction: The role of re-exposure duration. Learn. Mem. 13: 27-34.

Przybyslawski, J. and Sara, S.J. 1997. Reconsolidation of memory after its reactivation. Behav. Brain Res. 84: 241-246.

Przybyslawski, J., Roullet, P., and Sara, S.J. 1999. Attenuation of emotional and nonemotional memories after their reactivation: Role of $\beta$ adrenergic receptors. J. Neurosci. 19: 6623-6628.

Rainer, G. and Miller, E.K. 2000. Effects of visual experience on the representation of objects in the prefrontal cortex. Neuron 27: 179-189.

Ramirez, R.R., Gandhi, C.C., Muzzio, I.A., and Matzel, L.D. 1998. Protein synthesis-dependent memory and neuronal enhancement in Hermissenda are contingent on parameters of training and retention. Learn. Mem. 4: 462-477.

Riesenhuber, M. and Poggio, T. 2002. Neural mechanisms of object recognition. Curr. Opin. Neurobiol. 12: 162-168.

Rodriguez-Ortiz, C.J., De la Cruz, V., Gutiérrez, R., and Bermudez-Rattoni, F. 2005. Protein synthesis underlies post-retrieval memory consolidation to a restricted degree only when updated information is obtained. Learn. Mem. 12: 533-537.

Rossato, J.I., Bevilaqua, L.R., Medina, J.H., Izquierdo, I., and Cammarota, M. 2006. Retrieval induces hippocampal-dependent reconsolidation of spatial memory. Learn. Mem. 13: 431-440.

Sangha, S., Scheibenstock, A., Morrow, R., and Lukowiak, K. 2003. Extinction requires new RNA and protein synthesis and the soma of the cell right pedal dorsal 1 in Lymnaea stagnalis. J. Neurosci. 23: 9842-9851.

Sara, S.J. 2000. Retrieval and reconsolidation: Toward a neurobiology of remembering. Learn. Mem. 7: 73-84.

Spear, N.E. 1973. Retrieval of memory in animals. Psychol. Rev. 80: 163-194. 
Squire, L.R. and Alvarez, P. 1995. Retrograde amnesia and memory consolidation: A neurobiological perspective. Curr. Opin. Neurobiol. 5: $169-177$.

Squire, L.R., Slater, P.C., and Chace, P.M. 1976. Reactivation of recent or remote memory before electroconvulsive therapy does not produce retrograde amnesia. Behav. Biol. 18: 335-343.

Staubli, U., Faraday, R., and Lynch, G. 1985. Pharmacological dissociation of memory: Anisomycin, a protein synthesis inhibitor, and leupeptin, a protease inhibitor, block different learning tasks. Behav. Neural Biol. 43: 287-297.

Stollhoff, N., Menzel, R., and Eisenhardt, D. 2005. Spontaneous recovery from extinction depends on the reconsolidation of the acquisition memory in an appetitive learning paradigm in the honeybee (Apis mellifera). J. Neurosci. 25: 4485-4492.

Suzuki, A., Josselyn, S.A., Frankland, P.W., Masushige, S., Silva, A.J., and Kida, S. 2004. Memory reconsolidation and extinction have distinct temporal and biochemical signatures. J. Neurosci. 24: 4787-4795.

Viola, H., Furman, M., Izquierdo, L.A., Alonso, M., Barros, D.M., de Souza, M.M., Izquierdo, I., and Medina, J.H. 2000. Phosphorylated cAMP response element-binding protein as a molecular marker of memory processing in rat hippocampus: Effect of novelty. $J$. Neurosci. 20: RC112.

Wan, H., Aggleton, J.P., and Brown, M.W. 1999. Different contributions of the hippocampus and perirhinal cortex to recognition memory.

J. Neurosci. 19: 1142-1148.
Winograd, M. and Viola, H. 2004. Detection of novelty, but not memory of spatial habituation, is associated with an increase in phosphorylated cAMP response element-binding protein levels in the hippocampus. Hippocampus 14: 117-123.

Winters, B.D., Forwood, S.E., Cowell, R.A., Saksida, L.M., and Bussey, T.J. 2004. Double dissociation between the effects of peri-postrhinal cortex and hippocampal lesions on tests of object recognition and spatial memory: Heterogeneity of function within the temporal lobe. J. Neurosci. 24: 5901-5908.

Winters, B.D., Saksida, L.M., and Bussey, T.J. 2006. Paradoxical facilitation of object recognition memory after infusion of scopolamine into perirhinal cortex: Implications for cholinergic system function. J. Neurosci. 26: 9520-9529.

Wustenberg, D., Gerber, B., and Menzel, R. 1998. Long- but not medium-term retention of olfactory memories in honeybees is impaired by actinomycin D and anisomycin. Eur. J. Neurosci. 10: $2742-2745$.

Xiang, J.Z. and Brown, M.W. 2004. Neuronal responses related to long-term recognition memory processes in prefrontal cortex. Neuron 42: 817-829.

Received September 4, 2006; accepted in revised form November 7, 2006.

\section{Learning \& Memory}

www.learnmem.org 


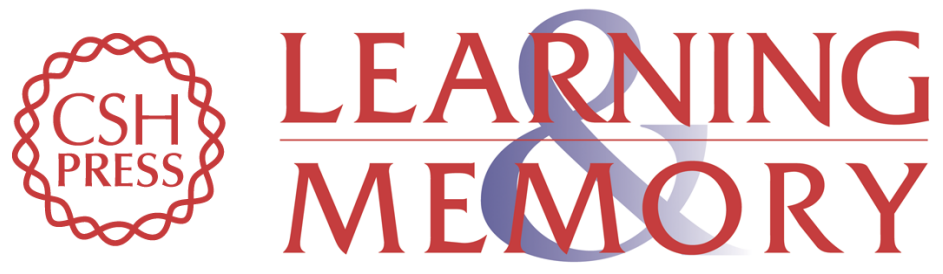

\section{On the role of hippocampal protein synthesis in the consolidation and reconsolidation of object recognition memory}

Janine I. Rossato, Lia R.M. Bevilaqua, Jociane C. Myskiw, et al.

Learn. Mem. 2007, 14:

Access the most recent version at doi:10.1101//m.422607

References This article cites 82 articles, 34 of which can be accessed free at: http://learnmem.cshlp.org/content/14/1-2/36.full.html\#ref-list-1

License

Email Alerting Receive free email alerts when new articles cite this article - sign up in the box at the Service top right corner of the article or click here. 